\title{
Opacity, Know-How States, and their Content
}

\author{
Josefa Toribio \\ ICREA-University of Barcelona

\begin{abstract}
The main goal of this paper is to defend the thesis that the content of know-how states is an accuracy assessable type of nonconceptual content. My argument proceeds in two stages. I argue, first, that the intellectualist distinction between types of ways of grasping the same kind of content is uninformative unless it is tied in with a distinction between kinds of contents. Second, I consider and reject the objection that, if the content of know-how states is non-conceptual, it will be mysterious why attributions of knowing how create opaque contexts. I show that the objection conflates two distinct issues: the nature of the content of know-how states and the semantic evaluability of know-how ascriptions.
\end{abstract}

\section{Keywords}

Accuracy conditions, intellectualism, know-how, non-conceptual content, opacity.

\section{Introduction}

Propositional knowledge, i.e., knowledge attributed to a subject by sentences with the form ' $S$ knows that $p$ ', is generally considered to be a propositional state whose content is a true proposition. What $S$ knows is the content of $S$ 's knowledge state. Knowing that $p$ is a factive state. When $S$ knows that $p, S$ stands in a particular knowing relation to a fact. There is less of a consensus on the appropriate analysis of practical knowledge, i.e., of the knowledge attributed to a subject by sentences with the form ' $S$ knows how to $\Phi$ '. According to Gilbert Ryle's $(1946,1949)$ classic anti-intellectualism, $S$ knows how to $\Phi$ in virtue of having some ability or disposition to $\Phi$. Additionally, the practical knowledge attributed to a subject by sentences

Disputatio, Vol. VII, No. 40, May 2015

Received: 20/05/2014 Revised: 13/04/2015 Accepted: 02/06/2015 
of the form ' $S$ knows how to $\Phi$ ' is regarded as a dispositional relation between a subject and the action type of $\Phi$-ing. By contrast, classic intellectualists hold both that $S$ knows how to $\Phi$ in virtue of S's having some propositional attitude(s) regarding $\Phi$-ing and that this type of practical knowledge is a propositional-attitude relation between a subject and a true proposition (see e.g. Brogaard 2009, 2011; Stanley 2011a, 2011b; Stanley and Williamson 2001). ${ }^{1}$ Classic intellectualism is the view challenged in this paper, especially Jason Stanley's version (2011a, 2011b). ${ }^{2}$

To briefly complete the intellectualist picture, we need a few more strokes. First, Stanley's preferred Fregean model of propositional-attitude ascription requires that true propositions are known under particular descriptions or modes of presentation. Furthermore, only true propositions are considered facts. The content of all our knowledge states involves, according to Stanley, these modes of presentation - these different ways of thinking about facts. Second, ways of thinking about facts include ways of thinking about ways of doing things. Third, and crucially, we think about the ways in which we do things either practically or demonstratively. The intellectualist ultimately explains the folk distinction between knowing how and knowing that in terms of this distinction between practical and demonstrative ways of thinking about ways of doing things. Here is the classic illustration. Even if Hanna does not know how to ride a bicycle, she may still know, while looking at John, who is riding a bicycle, that the way in which John rides it is a way for her to ride it. It would thus be true that Hannah knows that John's way is a way for her to ride a bicycle, while thinking about that way demonstratively, even though she does not know how to ride it (Stanley and William-

\footnotetext{
${ }^{1}$ I am following here the well-known characterization offered by Bengson and Moffett (2011a) in terms of two different dimensions: what grounds knowledge how and what is the nature of the knowledge thus grounded. See Bengson and Moffett (2011a, 2011b).

${ }^{2}$ I thus do not take myself to be challenging Bengson and Moffet's non-propositional, objectualist intellectualism, according to which "knowledge how to $\varphi$ is a nonpropositional, objectual relation between a subject and an item - a method or way of $\varphi$-ing, say - that one has in virtue of having a certain propositional attitude regarding $\varphi$-ing" (Bengson and Moffett 2011a: 164). In what follows, I will use 'intellectualism' to refer to classic intellectualism as characterized above.
} 
son 2001: 428-9). For the intellectualist, the folk notion of knowing how is instead accounted for in terms of a specific, practical, as opposed to demonstrative, way of thinking about ways of doing things. When a subject knows how to $\Phi$, she knows that $w$ is a way for her to $\Phi$. This kind of propositional knowledge is first-person, de se knowledge of a way of $\Phi$-ing, while thinking of that way practically and not demonstratively.

If intellectualism is true, the knowing-that / knowing-how distinction is a distinction between types of ways of thinking about the same kind of conceptual content. In what follows, I argue that such a distinction between types of ways of thinking is uninformative unless it is tied in with a distinction between kinds of contents. In the version of anti-intellectualism I endorse, $S$ knows how to $\Phi$ in virtue of S's being in a cognitive state whose content is, unlike the content of know-that states, non-conceptual. The non-conceptual content of know-how states has, however, correctness conditions. If $S$ knows how to $\Phi$, then $S$ is in a cognitive state whose (accurate) non-conceptual content is a way of $\Phi$-ing for $S$. In this anti-intellectualist version, the practical knowledge attributed to a subject by sentences of the form ' $S$ knows how to $\Phi$ ' not only is grounded in, but is a non-propositional attitude that relates the subject to a mental state with non-conceptual content. The attitude is non-propositional because it does not relate the subject to a proposition. ${ }^{3}$ This non-dispositionalist version of anti-intellectualism is thus consistent with the claim - wrongly made an exclusive mark of intellectualism - that all knowledge is knowledge of facts, for knowledge how is placed back into cognitive territory in the realm of accurate representations.

\footnotetext{
${ }^{3}$ Although, on the view defended here, the attitude relates the subject to a state whose content is accuracy assessable. From the claim that the content of know-how states is accuracy assessable, it does not follow that they have propositional structure or conceptual content. The notion of content and the notion of correctness conditions go hand in hand, regardless of whether the content is conceptual or non-conceptual. Furthermore, to claim that the attitude in which know-how consists is non-propositional does not amount to claiming that knowhow states have relatively non-conceptual content. The notion of non-conceptual content is here understood as absolutely non-conceptual, i.e., as a monadic property of the content of know-how states as opposed to a relation between the subject and the state's content - the mark of relatively non-conceptualism. Please see below.
} 
Note that, in arguing that know-how is a non-propositional attitude, the term 'propositional' may be taken to be ambiguous between (at least) two readings. On one reading, to claim that know-how states lack propositional structure means that they lack sentencelike, i.e., canonical compositional structure. This is a syntactic reading of 'propositional'. On a second reading, 'propositional' means having conceptual content, in particular, content that is constituted by Fregean concepts, which is truth-apt. On this second reading, to claim that know-how is a non-propositional attitude means that the content of know-how states is not semantically evaluable. The position defended here characterizes the content of know-how states as non-propositional in the first of the two readings without thereby ruling out the idea that the content of such states has correctness conditions. The idea, endorsed by some neo-Fregean nonconceptualists (e.g., Heck 2007) with regard to the content of perceptual representations, is that the possession of such a different (non-propositional) structure is so cognitively relevant in the subject's mental economy that the content of the relevant states - know-how states in this case - is of a different (non-conceptual) kind.

Since the intellectualist endorses the view that know-how states have propositional content (in the second sense) as their content, while also allowing that there may be representations without propositional structure in virtue of which we know how to $\Phi$, it may appear as if the disagreement between the present proposal and the intellectualist's is purely verbal — a disagreement about whether or not what is here characterized as accuracy-apt non-conceptual content qualifies as propositional or not.

This is an important point and one that should be addressed right away so as to clarify the spirit of the view defended in this paper. First of all, the claim that the content of know-how states is nonconceptual should be understood as encompassing two different, yet intimately related, ideas: that know-states do not have a canonical decomposition and that the content of such states does not have Fregean concepts as constituents. Since Fregean concepts lie at the heart of the intellectualist proposal as constituents of the content of know-how states, the dispute here is not merely verbal. The main difference between e.g. Stanley's (2011b) account and the one suggested here lies precisely here. Since intellectualists hold that both 
know-how and know-that states have the same kind of (conceptual) content, they need to appeal to practical modes of presentation in order to account for the distinctive cognitive abilities involved in knowledge how. This, I shall argue, does not seem to be informative. By contrast, the view defended in this paper, according to which the content of know-how states is accuracy-apt but non-conceptual offers, I contend, a more fruitful, parsimonious and explanatorily powerful alternative.

As part of my defence of anti-intellectualism, I will consider and reject an objection that has been brought against the view that the content of know-how states is non-conceptual. The objection is that, if the content of know-how states were non-conceptual, it would be mysterious why attributions of knowledge-how create opaque contexts. I show that the objection conflates two distinct issues: the nature of the content of know-how states and the semantic evaluability of know-how ascriptions. Once the conflation is debunked, the opacity of know-how attributions presents no mystery.

\section{Ways: Wherein lies the difference?}

As I have just outlined, intellectualists do not deny the folk distinction between knowledge how and knowledge that. They deny that the folk distinction entails there being two types of knowledge, i.e., they deny that there are two different types of knowledge states with different types of content. To explain the folk distinction, the intellectualist appeals, instead, to a difference in ways of thinking which involve the (same kind of) conceptual content. But if knowhow states are states of the same cognitive type as know-that states, and are only set apart by a practical way of thinking that involves the very same kind of content, it is imperative to provide an account of why such a practical — as opposed to a demonstrative — way of thinking about the same kind of content turns out to be so different. The plausibility of the intellectualist picture depends on its being able to provide such an account. Yet, all the intellectualist has to offer instead is a characterization of what it means to think of a way of doing something practically; it means for that way to play a certain functional role in our mental economy. "Explaining what it is to think of a way of doing something in a practical way is ... a matter of spelling 
out the distinctive practical functional role that way occupies in the mental life of the speaker" (Stanley, 2011b: 124).

Spelling out the functional role of our way of $\Phi$-ing, however, does not seem informative unless it is accompanied by an account of why such a way of $\Phi$-ing plays such a distinctive functional role. ${ }^{4}$ For the elucidation of the functional role of this way of doing things would inevitably involve the subject's possession of some skill or skill-related disposition, thus making the intended explanation come extremely close to merely being a restatement of the original puzzle. In other words, the intellectualist distinguishes between demonstrative and practical modes of presentation of same-content, same-type states to account for the pre-theoretical distinction between theoretical knowledge and knowledge how - a pre-theoretical distinction reflected in their different functional roles. Yet, if, for me to know, under a practical mode of presentation, that $w$ is a way to $\Phi$ just is for $w$ to occupy a certain functional role in my mental life, then explanadum and explanans come to resemble each other dangerously. Indeed, Stanley and Williamson acknowledge being unable to clarify the idea of practical ways of thinking about ways of doing things in a nontrivial manner. Their claim that "thinking of a way under a practical mode of presentation undoubtedly entails the possession of certain complex dispositions" (Stanley and Williamson 2001: 429) does not throw much light on the issue. For the intellectualist (see also Stanley 2011b) also holds that all propositional knowledge, and hence also knowledge that consists in thinking about a way of doing things under a demonstrative mode of presentation entails the possession of dispositions, albeit perhaps different dispositions. ${ }^{5}$

\footnotetext{
${ }^{4}$ One could argue that since the relation between practical modes of presentation and the relevant functional roles is constitutive, i.e., since for me to know, under a practical mode of presentation, that $w$ is a way to $\Phi$ just is for $w$ to occupy a certain functional role in my mental life, this why-question would be misguided. However, not all claims about $\mathrm{X}$ being just $\mathrm{Y}$ should be considered question-stoppers. Even though water just is $\mathrm{H}_{2} \mathrm{O}$, it is sensible and pertinent to ask why being composed of $\mathrm{H}_{2} \mathrm{O}$ molecules makes water behave the way it does. This is the nature of the why-question I raise here. I thank an anonymous referee for pointing this out.
}

${ }^{5}$ As it is all too well known, the intellectualists' main support of their view comes from semantic evidence based on the analysis of sentences containing em- 
Furthermore, since for $\mathrm{X}$ to play functional role $\mathrm{Y}$ is for $\mathrm{X}$ to play a specific causal role, i.e., for $\mathrm{X}$ to behave in a particular way, the characterization of practical modes of presentation in terms of the functional role of our ways of doing things ends up being rather unwieldy at best. It amounts to saying that our ways of doing things behave in a particular way. Or to be more precise, it amounts to saying that, for me to know, under a practical mode of presentation, that $w$ is a way of $\Phi$-ing, is for my way of $\Phi$-ing to behave in a particular way.

Now, let's contrast the intellectualist picture with its alternative: anti-intellectualism. Here, again, we start with a pre-theoretical distinction between theoretical knowledge and knowledge how which reveals itself in their different functional roles. However, instead of appealing to (different) modes of presentation of the same (type of) content, which are in turn characterized in terms of the functional roles of our ways of doing things, we appeal to states with different kinds of content. We thus avoid falling into triviality territory in the way just described, and get a straightforward and informative answer. The question of why theoretical and practical knowledge appear to be so different (play such different functional roles) gets an informative answer when we say that know-that and know-how states have contents of different types. The content of the state we are in when we are in a know-that state is so different in kind to the content we are in when we are in a know-how state that the question of why, pre-theoretically, theoretical knowledge and knowledge how behave so differently gets a straightforward answer. Occam's razor favours anti-intellectualism.

Classic anti-intellectualists, needless to say, complete this claim with a characterization of know-how states as abilities or disposition to skilfully and reliably act (Ryle 1946, 1949). ${ }^{6}$ Crucially, they

bedded questions. The evidence makes it clear, they argue, that knowing-how attributions are best analysed as expressing a relation between a subject and a (true) proposition. Semantic evidence also underwrites their appeal to an ontology of ways of thinking (see e.g. Stanley 2011b: ch. 4). Yet, for reasons that will become clear in Section 4, I will avoid bringing to bear any of this semantic evidence into the present discussion.

${ }^{6}$ Although perhaps counterfactually (see Hawley 2003). 
also endorse the view that know-how and know-that states are different types of states because they have different kinds of content. While know-that states have conceptual content, know-how states have non-conceptual content-a type of content that they take to be not only non truth-apt, but not amenable to rationality. Here is Dreyfus on this matter: "embodied skills, when we are absorbed in enacting them, have a kind of content which is non-conceptual, nonpropositional, non-rational (even if rational means situation specific) and non-linguistic" (Dreyfus 2007: 360).

In contrast to the classic anti-intellectualist view, I propose a accuracy assessable version of anti-intellectualism, according to which $S$ knows how to $\Phi$ in virtue of bearing a non-propositional attitude to a personal-level cognitive state with non-conceptual content that accurately represents $S$ 's way of $\Phi$-ing. This proposal provides, on the one hand, an informative answer to the key question of why knowhow states play a distinctive functional role that issues in a characteristic practical way of doing things. They play such a distinctive functional role because know-how states have non-conceptual content, i.e., content that is different in kind to the content of know-that states, and they are, for that reason, states of a distinctive type. ${ }^{7}$ The proposal sits comfortably, on the other hand, with the idea that skilful, intelligent action is guided by knowledge of facts - as opposed to a subject's ability or embodied skill- since know-how states are characterized as personal-level states, which accurately represent how to do something for a subject.

This version of anti-intellectualism avoids the two classic sets of criticisms usually brought against its classic cousin. The first set questions whether the possession of an ability could be either a necessary, or a sufficient condition, for knowing how - what Bengson and Moffett (2011a) call, respectively, the 'pervasive inability' and the 'ignorant reliability' problems. Cases like the infamous ski in-

${ }^{7}$ My considerations here are solely methodological. Of course, it should also be clarified how the fact that the content of know-how states is non-conceptual explains why know-how states have such a distinctive functional role. I address this issue in Section 3. The answer, in a nutshell, is this: paradigmatic properties of knowledge how - its essential practical nature and its frequent resilience to linguistic inferential reasoning — are best accounted for by relying on this theoretical notion. 
structor, who seems to know how to do ski stunts while not being and never having been able to do them, illustrate the pervasive inability problem. They challenge the view that abilities are necessary for knowing how. Cases like the (in)famous novice skater, who reliably and successfully performs complicated multiple jumps, despite her seriously mistaken views about how to actually do them, illustrate the ignorant reliability problem. These latter cases challenge the view that abilities are sufficient for knowing how. The version of anti-intellectualism proposed here, by making S's know-how state a cognitive state instead of an ability, makes the problems of pervasive inability and ignorant reliability disappear.

The second set of criticisms against classic anti-intellectualism targets the idea that the content of know-how states is not semantically evaluable. The concern seems to be that, were we to characterize the content of embodied skills as non-conceptual, in this sense, know-how states would be implausibly located at the sub-personal level, and skilful action would fall outside the guidance of intelligence, outside the sphere of rationality. The version of anti-intellectualism I endorse here eases the burden of this type of concern-let us call it 'the sub-personal worry' - by means of a basic philosophical tenet, namely, that contentful mental states are necessarily states with associated accuracy or correctness conditions - whether their content is conceptual or not. To talk about the content of a mental state is just to talk about the way the state represents the world as being. This accuracy assessable non-conceptual content of knowhow states is thus subject to rationality constrains, and could guide skilful action in virtue of its correctly or accurately representing a subject's own way of doing things. ${ }^{8}$ In this version of anti-intellectualism, knowing how to $\Phi$ is a relation between a subject and a nonpropositional object, the subject's way of $\Phi$-ing, which is correctly represented by a personal-level state whose non-conceptual content consists precisely in that way of $\Phi$-ing. The commitment to the representational, albeit non-conceptual, nature of know-how states does not thus belie the idea that, when we learn how to $\Phi$, we learn a fact about the world - it just challenges the assumption that only true propositions can be facts.

${ }^{8}$ I further discuss the sub-personal worry in the next Section. 
I have arrived at this version of anti-intellectualism without examining any of the emblematic properties of knowing how, or identifying what makes non-conceptual content an appropriate notion to capture such properties. In the next Section, I will give reasons for thinking that non-conceptual content is indeed such a suitable notion. I will also consider and reject an argument against this view. But before doing that, let me emphasize that my considerations are largely methodological. The persuasiveness of the proposal suggested here hinges on its being able to provide an informative answer to the central question of why practical ways of thinking about doing things play such a distinctive functional role. By identifying ways of thinking with the functional role of the states themselves, the proposal offers an informative answer to this question, while avoiding the sets of objections usually raised against classic anti-intellectualism.

\section{The non-conceptual content of know-how states}

The claim that the content of know-how states is non-conceptual is here understood as a claim about the nature of the content of such states. The content is non-conceptual because it is essentially different in kind to the content of know-that states, i.e., it is essentially different in kind to Fregean propositions. Since Fregean propositions essentially have a canonical compositional structure and are composed of (Fregean) concepts, non-conceptual content, as understood here, is content that has no canonical compositional structure and is not composed of (Fregean) concepts.

That a representation lacks a canonical compositional structure means that the representation is decomposable, but its content and syntactic structure is not determined by the content and the syntactic structure of their constituents (see Fodor 2007). ${ }^{9}$ The claim that know-how states have non-conceptual content thus amounts to claiming that they are like pictures or cognitive maps, iconic. As such, they have an ability-based flavour linked - but not constitut-

${ }^{9}$ Although I take the idea of canonical representation from Fodor, I do not thereby consider concepts as psychological representational primitives or "words" in a "language of thought". The relevant, contrasting notion of concept here is neo-Fregean, i.e., concepts as the abstract constituents of content. 
ed — by the set of skills that a subject deploys when negotiating a domain. This characterization of non-conceptual content is a form of what Speaks (2005) calls 'absolutely non-conceptual content' and Heck (2000) refers to as 'the content view' of non-conceptualism.

My relying heavily on the idea of canonical decomposition to characterize the content of know-how states as non-conceptual may invite the complaint that I am conflating syntax with semantics. It may be said that the structural properties of mental states of a given type do not tell us anything about the nature of their content. In fact, the move from state-structure to content-nature may appear to be a version of the vehicle-content confusion: the confusion of thinking that the representational properties of states of a certain type reflect their causally relevant structural properties. However, within a neo-Fregean account of concept and concept possession the move is fairly standard: conceptual content is usually characterized as content that is structured so as to satisfy the generalizations supported by some strong principle of compositionality, such as Evans (1982) Generality Constraint (GC henceforth). So, if there are indeed good reasons to grant this dialectical move in the case of conceptual content, the claim that nonconceptual content is content so canonically un-structured so as to fail to satisfy the generalizations supported by GC shouldn't be regarded as theoretically suspicious.

The claim that conceptual content has Fregean concepts as constituents entails the idea that grasping a concept $F$ is to exercise an ability - the ability to think of a thing as F. Possessing such an ability, in turn, partially explains the subject's ability to entertain thoughts in which F occurs. Within a neo-Fregean account of conceptual content, to claim that the content of a state is conceptual is to be committed to the view that the content of perceptual experiences obeys GC in its stronger form (Evans 1982: 104, ft. 21), i.e., that the ability of a subject to think that a is $\mathrm{F}$ is not only composed of, but is also explained by, two distinct abilities: the ability to think of a and the ability to think of a thing as F (see Heck 2007: 123).

It is against the background of this neo-Fregean picture of conceptual content that the essentially contrastive notion of non-conceptual content has to be understood here. In claiming that the content of know-how states is non-conceptual, i.e., in claiming that their content is like the content of icons or cognitive maps, we are 
denying that the content of know-how states has Fregean concepts as constituents and hence we are denying that, in order to know how to $\Phi$, the subject has to possess the set of complex abilities that should be deployed whenever entertaining thoughts containing the relevant concepts involved in $\Phi$-ing. Instead, the subject deploys a different set of cognitive skills: those involved in the negotiation of a practical domain.

Richard Heck (2007) illustrates this characterization of non-conceptual content in terms of cognitive maps as follows. An essential feature of cognitive maps, Heck (2007) claims, is that their spatial primitives, i.e., the landmarks, are always represented as a set of movements. But, this being the case, when we credit a subject with a spatial representation about an object $a$ at location $F$, this does not commit us to the idea that the subject can represent $a$ independently of $F$. Hence it does not commit us to the idea that the subject should also be able to represent $a$ at location $G$ or another object $b$ at location F. Cognitive maps are not representations with canonical compositional structure. The lack of a canonical compositional structure reflects the lack of a certain type of cognitive ability, but not of all cognitive abilities. The claim that to know how to $\Phi$ is to have a cognitive map about $\Phi$-ing amounts to claiming that to know how to $\Phi$ is to possess a certain cognitive ability pertaining to the practice of $\Phi$-ing - a cognitive ability that may not be linguistically expressible or revisable on the basis of inferential and evidential relations, and that pertain to the set of skills subjects deploy when engaging in an activity. ${ }^{10}$

The natural question is: why would non-conceptual content, thus understood, be a suitable candidate for the content of know-how

${ }^{10}$ Heck also exemplifies the lack of canonical structure of cognitive maps with a case of knowing how: "having a cognitive map of one's environment is quite different from having a collection of explicit beliefs about it. One manifestation of this fact is that one can "know how to get somewhere" and yet have no idea how to give someone directions for getting there - except, perhaps, by imagining the route one would take, thus putting one's cognitive map to use in imagination." (Heck 2007: 128). Heck, however, does not endorse the idea that know-how states are cognitive maps. Neither does he offer an argument in favor of the non-conceptual nature of the content of know-how states, as Stanley suggests (2011b: 172). 
states? The standard motivation behind the appeal to non-conceptual content in discussions of knowing how is the idea that the actionoriented aspects of cognition call for an explanatory tool that would allow us to ascribe know-how states to subjects without them having to possess the concepts used to correctly characterize such states. My argument, however, does not rely, directly, at least, on this kind of considerations. In some cases, the action-oriented aspects constitutive of knowing how do require that the relationship between subjects and their know-how states be such that they need to possess the concepts involved in a correct characterization of their content. I thus acknowledge the view, often endorsed by the intellectualist, that even if "I do not have to have an accurate descriptive conceptualization of my way of $\Phi$-ing, in order to know how to $\Phi$... I do need to have the concept associated with the activity of $\Phi$-ing" (Stanley, 2011b: 170).

It may indeed seem absurd to think that someone can, for instance, know how to fly a 747 jet without having to possess the concepts associated with the activity of flying a 747 jet. At the same time, the plausibility of this claim would only show that knowing how to do things, for a large class of actions, is not possible without having acquired certain concepts. It does not show that what justifies the ascription of knowing how is the subject's possession of such concepts. Subjects may indeed need to possess certain concepts for knowing how to do certain things, even if such conceptual abilities do not constitute their know-how. This is, of course, at least partly, why the intellectualist appeals to practical ways of thinking about ways of doing things: to provide an explanation not based strictly on concept possession. After all, I may be related to a proposition that contains as its constituent the concept of FLYING A 747 JET only under a demonstrative mode of presentation. Yet, since the attempt to clarify the notion of practical ways of thinking in terms of their functional role is - as I have argued in the previous Section-explanatorily idle vis-à-vis the characteristic features of know-how, the most natural and straightforward explanation of such characteristic features will appeal to the different kind of (non-conceptual) content involved in the know-how states.

The appeal to states with non-conceptual content is not only methodologically fruitful. The notion of non-conceptual content 
also seems to be especially well suited for characterizing the content of know-how states, as the lack of a canonical composition entails that the cognitive abilities that grant ascription of knowing how do not involve representational structures that support linguistic or quasi-linguistic inferential reasoning - something commonly associated with knowledge how. Non-conceptual content seems to be the appropriate notion for characterizing the content of representational states that are intimately connected to the subject's abilities to act upon objects or to perform a particular task. The arguments stressing this feature are abundant in the anti-intellectualist camp, but have suffered from a non-cognitivist, ability-based, take on the notion. Yet, as I clarified earlier, states with non-conceptual content, on the proposed account, have correctness conditions. Like cognitive maps, they can be correct or incorrect, accurate or inaccurate representations. States with non-conceptual content, although not governed by the compositional semantics applicable to natural language, still can enter, on the account defended here, into rational cognitive processes. ${ }^{11}$

Interestingly, intellectualists like Jason Stanley (2011b) acknowledge that there is a role for the notion of non-conceptual content in their picture. Yet, it is the role, he claims, of enabling the appropriate propositional mental states through the operation of certain sub-personal mechanisms. Stanley thus attempts to undermine the arguments of those who rely, for instance, on the neuropsychology of motor-intentional behaviour to make a case against the propositional nature of the content of know-how states (see e.g. Kelly 2000; Toribio 2008a), by pointing out that whatever role non-conceptual content plays at the sub-personal level-i.e., at the level of the mechanisms involved in skilful action-, that role is perfectly consistent with the intellectualist view. When discussing the case of DF-a patient, who due to carbon-monoxide poisoning is completely unable to recognize the size, shape and orientation of visual objects, while nevertheless being able to execute tasks such as posting a card through a slot rotated at different angles - Stanley claims:

\footnotetext{
${ }^{11}$ See Rescorla 2009 for a defence of the possibility of rational cognitive processes involving computations defined over a particular type of cognitive map.
} 
DF's knowledge of how to put a card into a slot is propositional knowledge that is based on a non-conceptual understanding of the orientation of the slot ... She is able to have propositional attitudes about a way of posting a card into a slot in virtue of this non-conceptual understanding of orientation. (2011b: 172)

Later on, while briefly discussing Heck's view about the non-conceptual content of cognitive maps, Stanley insists on this idea:

Perhaps we need non-conceptual content to explain some of the ways of thinking that constitute the content of my knowledge of how to grasp a doorknob, or my knowledge of how to get to Boston. It may be that non-conceptual content is needed to have the propositional attitudes that are required to guide an action, in order for that action to be skilled. This role of non-conceptual content, as enabling propositional mental states, raises no problem at all for the thesis that an action is skilled, or intelligent, in virtue of being a manifestation of propositional knowledge. (2011b: 173)

Stanley's concern is a version of the sub-personal worry. He seems to think that, were we to characterize the content of know-how states as non-conceptual, we would thereby be committed to a view of knowing how that locates it outside the sphere of intelligence-outside rationality. The general issue of whether there could be intelligence or reason-guided action outside the domain of conceptual thought goes beyond the scope of this paper. Let me make, however, two brief remarks about this issue.

First, Stanley's interpretation of Heck's view of non-conceptual content is far too hurried. Stanley's argument is summed up in this quote:

The fact that some representations take the form of cognitive maps does not mean that they are non-conceptual. A cognitive map can determine one kind of mode of presentation of a way of getting somewhere. Modes of presentation do not need to be characterized in descriptive terms. Knowing how to get to Boston is knowledge of a proposition concerning a way of getting to Boston, where the functional role of that way is specified via features of the cognitive map. (Stanley 2011b: 172-173)

The argument is, however, deeply flawed, as it is based on the (mistaken) idea that the structural properties of the states that can be said to be cognitive maps are not related at all to their content being conceptual or non-conceptual. Yet, once you take the contrasting notion of conceptual content to be a Fregean notion, to say of a state 
that it takes the form of a cognitive map implies that the constituents of such a state do not have a propositional structure. The suggestion is that, by virtue of not having a propositional structure, cognitive maps cannot enter into the same kind of inferential relationships as states whose content has a canonical decomposition. As Heck (2007: 128) reminds us, cognitive maps are like geographical maps in that "one cannot, for example, form arbitrary Boolean combinations of maps: There is no map that is the negation of my cognitive map of Boston; there is no map that is the disjunction of my map and my wife's; and so forth." It is thus part and parcel of the idea of a cognitive map that its content is non-conceptual, in this strong sense. It is precisely this feature that explains why know-how states, as states that take the form of cognitive maps, play their distinctive functional role.

When Stanley claims (2011: 168) that endorsing a notion of nonconceptual content for know-how states is consistent with his intellectualism, he has in mind a form of what Speaks (2005) calls 'relatively non-conceptual content' or what Heck (2000) refers to as 'the state view' of non-conceptualism. On the state-view reading, 'non-conceptual' is a dyadic property that relates the subject to the content of the states she is in - the property of not needing to possess the relevant concepts. On this reading, the content of the know-how states can indeed be a proposition. Hence, the consistency between the two views. However, as I have stressed here, when non-conceptualism is taken in the stronger, absolute, content-view sense, and the contrasting notion of conceptual content is construed along neo-Fregean lines in the way I do, the consistency vanishes, as this view would entail that the subject could exercise cognitive abilities she does not possess (see Toribio 2008b).

Second, and more directly related to Stanley's sub-personal worry. Both Heck's view of cognitive maps as paradigmatic representations with non-conceptual content and the view of know-how states defended here, as states that take the form of cognitive maps, locate the operation of these representations at the personal level of the subject's cognitive life. Stanley's claim that the role of non-conceptual content is that of 'enabling propositional mental states' suggests that he instead conceives of non-conceptual content as the content of the states of the sub-personal systems that subserve the putative 
propositional states in which know-how states consist. A sub-personal system is a physical mechanism - usually a part of an organism's brain - that processes information in ways that are not available to the organism itself. The enabling role that Stanley assigns to nonconceptual content - as the content of sub-personal states - is thus a causal role. Indeed some authors (see e.g. Bermúdez 1995) have argued that the content of the sub-personal computational states posited by e.g. information-processing accounts of vision is non-conceptual. Thus understood, the appeal to states with non-conceptual content to explain knowledge how is consistent with intellectualism. However, the consistency of intellectualism with a characterization of non-conceptual content as the content of sub-personal level states, does not speak against there also being personal-level states with non-conceptual content which stand in a constitutive relationship, as opposed to a causal relationship, to knowledge how.

Crucially, on this latter understanding, it would make sense to claim, with Stanley, that DF knows how to put the card into the slot in virtue of a non-conceptual understanding of the orientation of the slot, without thereby entailing, as Stanley does, that the role of nonconceptual content is purely causal - an enabler of the propositional attitude in which know-how consists. ${ }^{12}$ Although sometimes 'in virtue of' has such a causal slant, to claim that something is the case in virtue of something else usually carries with it the mark of a very different type of explanation - a grounding explanation. Grounding explanations are "a distinctive kind of metaphysical explanation, in which explanans and explanandum are connected, not through some sort of causal mechanism, but through some constitutive form of determination" (Fine, 2012: 37). To claim that DF knows how to put a letter through the box in virtue of her non-conceptual understanding of the orientation of the slot does not reduce knowing how to the tokening of a sub-personal state. Neither does it give necessary and sufficient conditions for her know how. If, as Gideon Rosen (2010:

\footnotetext{
${ }^{12}$ Stanley's interpretation of DF's case seems to conflate the idea of subjects' having no conscious access to their know-how states with the idea that such states cannot guide intelligent action. Some unconscious states - typically e.g. unconscious beliefs - may and do indeed guide subjects' intelligent (and, sometimes, not so intelligent) behavior in complex and subtle ways, and they belong, for this reason, to the personal level of our cognitive lives.
} 
118) claims, that $p$ obtains in virtue of $q$ entails that $q$ necessitates $p$, then DF's non-conceptual understanding may be considered only a partial ground. The full ground of the fact that DF knows how to put a card into a slot may then have to include the fact that DF is capable of having some other propositional attitudes - e.g. the belief that Kelly (2002: 388) reports DF expressing with the sentence: 'I believe the slot is oriented this way.' The claim that DF knows how to put a card into a slot in virtue of a non-conceptual understanding of the orientation of the slot may thus be compatible with the idea of there being sub-personal states enabling some relevant propositional attitudes (how could there not be?). But it should be read, on the accuracy assessable version of anti-intellectualism defended here, as conveying that DF's knowledge how is grounded in - and not caused by- her non-conceptual understanding of the orientation of the slot. Such a non-conceptual understanding is constituted by DF's bearing a non-propositional attitude to a personal level cognitive state with a non-conceptual content that correctly represents DF's way of putting the card into the slot.

Stanley also offers an argument against what seems to be a version of this latter view (Stanley 2011b: 167-170). If the content of knowhow states were non-conceptual, it would be mysterious, Stanley claims, why attributions of knowing how create opaque contexts (Stanley 2011b: 169). I turn to this argument in the next Section.

\section{Opacity}

Propositional attitude contexts are characteristically opaque. They are linguistic expressions in which the substitution of co-referring terms changes the truth-value of the sentence - they create nonextensional contexts. The idea that attributions of knowing how create opaque context was already present in Stanley and Williamson (2001: 416), but it is Stanley (2011b) who addresses the issue in more detail. In order to do so, he relies on David Carr's famous example of a dancer who knows how to perform a particular dance, which happens to be, unbeknownst to him, a Semaphore recital of Gray's 'Elegy':

Suppose a famous dancer was to perform before an audience, an item from his repertoire to which he has himself given the following title: 
(12) A performance of Improvisation No. 15

To the astonishment of a member of his audience who just happens to be an expert on communications, the movements of the dancer turn out to resemble an accurate (movement perfect) semaphore version of Gray's "Elegy", though the dancer is quite unaware of this fact. We may describe what is seen by the audience member as follows:

(13) A semaphore recital of Gray's "Elegy".

Although we can describe the dancer as knowing how to bring about (12) we cannot reasonably suppose that he also knows how to bring about (13). Even though (12) and (13) are...but different characterizations of the same action, we cannot safely switch these characterizations in knowing how contexts. So it appears that sentences about knowing how, unlike those about ability, are truly non-extensional. (Carr 1979: 407-8)

Stanley takes Carr's example to be conclusive about the opacity of knowing-how attributions and argues: "[i]f knowing how to do something is non-conceptual ... it would be utterly mysterious why attributions of knowing how create opaque contexts" (Stanley 2011b: 169). Stanley's argument can thus be formulated in the following way:

(1) If ascriptions of know-how are opaque, then the content of know-how states is conceptual.

(2) Ascriptions of know-how are opaque.

(C) Therefore, the content of know-how states is conceptual.

To probe the argument, one may adopt one of the two following strategies. First, to deny premise (2) and argue that, if (12) and (13) are indeed coextensive, then the dancer knows how to bring about both (12) and (13). Second, to deny premise 1. Even though I believe ascriptions of knowledge how are indeed opaque, it would be helpful to see how someone interested in pursuing the first of the two strategies might argue for it. It will be helpful because it will further clarify the main distinction between classic anti-intellectualism and the proposal defended in this paper.

The obvious move for someone interested in denying premise (2) is to try to convince us that the dancer knows how to bring about 
both (12) and (13), but does not know that he knows. We would have to assume, of course, that the dance is not just an unrepeatable improvisation, as the name may, perhaps misleadingly, suggest. It could then be argued that, if the expert on communications were to inform the dancer that he just danced a Semaphore recital of Gray's 'Elegy', the dancer would know, on the spot, how to dance the Elegy without having to learn anything else. This would allegedly show that what the dancer lacks is a piece of declarative knowledge, not knowledge how.

Perhaps some of the awkwardness one feels when trying to imagine someone dancing a choreography as complex as a choreography of the Elegy would look like without knowing that each of the movements corresponds to a symbol in Semaphore lies in the fact that the Semaphore telegraphic system has, like any other language, a canonical compositional structure. Would simpler cases of co-extensional descriptions of activities make the dialectical move of this first strategy more attractive? Think of the expert knitter who comes out with what he takes to be a rather original and improvised knitting stitch pattern, which he calls 'Pattern No. 5.' To the astonishment of the knitter's knowledgeable circle of friends, Pattern No. 5 is only a reproduction of what everyone in the knitting circles knows as a mock cable. Since knitting patterns, unlike the Semaphore system, lack a canonical decomposition, we may feel more inclined to grant that our expert knitter knows how to knit a mock cable; he just does not know that he knows. So, if a knitter comes up with an improvised pattern, which belongs, unbeknownst to him, to some extended repertoire, the opacity claim seems to lose some of its bite. But not all of it. If e.g. we asked our knitter to knit a mock cable before he is told that what he does is precisely that, he would not be able to comply with our request. In fact, any ascription of knowledge, including knowledge how, results in classic opaque contexts, because knowledge is a semantically evaluable state. It is only when we think about these cases along the lines of an ability-based characterization of knowledge how that we get conflicting intuitions. Yet, as we saw, an ability-based characterization of know-how is subject to powerful objections. It can also prompt, we can add now, misguided intuitions with regard to the opacity of know-how ascriptions.

The second, much more promising strategy, is the one I would 
like to pursue here. As I said, it consists in denying premise (1) of the argument above. It is simply false that if ascriptions of know-how are opaque, the content of know-how states is conceptual. The conditional would be true just in case the only states with semantically evaluable content were states with conceptual content. This underlying assumption, however, would only hold if we thought of non-conceptual content in the way classic, Dreyfus style, anti-intellectualism does. This seems to be what Carr has in mind at the end of the text quoted above: "[s]o it appears that sentences about knowing how, unlike those about ability, are truly non-extensional" (Ibid, my italics). Yet, as I have made clear earlier, it is part and parcel of the notion of a contentful mental state that it is representational. Contentful states, including contentful states whose content is non-conceptual, represent the world as being a particular way — pace Dreyfus - and thus have correctness conditions. Whether their content is conceptual or non-conceptual is determined by their syntactic structure, i.e., by whether or not the content is canonically decomposable and by the nature of its constituents. This difference, in turn, explains the distinct ways in which these states behave in the subject's mental economy. If the position defended in this paper is right, the characteristic functional role of know-how states in a subject's mental economy (the explanandum in a theory about know-how) is best accounted for by appealing to an accuracy assessable notion of non-conceptual content - an explanans which, unlike practical modes of presentation of the same kind of conceptual content, is not just a reinstatement of the explanandum. The alleged truth of premise (1) is thus based on a conflation of two very different issues. One is whether ascriptions of know-how states are semantically evaluable. They are. The other is whether the content of know-how states is conceptual: not necessarily.

The root of this conflation arguably lies in the idea that, in defending the non-conceptual nature of the content of a state, theorists are thereby committed to the idea that we cannot formulate or communicate such content. But, of course, this is not true. The correctness conditions of a state (regardless of the nature of its content) will always be part of a linguistic characterization. That the characterization is linguistic and hence has propositional structure and conceptual content does not mean that the content it refers to has to 
share the same properties. The obvious unavoidability of theoretical descriptions for expressing the correctness conditions of know-how states does not amount, in and of itself, to agreeing with the intellectualist that know-how states are propositional attitudes after all. ${ }^{13}$ We, as theorists, describe the knower as related to something that is expressed in propositional form, but the know-how attitude remains non-propositional because know-how is, on this account, the kind of representational state that is about things/facts (ways of doing things) not in virtue of relating the subject to a proposition concerning those facts, but in virtue of the subject's being in a know-how state with accurate non-conceptual content.

\section{Conclusion}

Once opacity is shown to be a red herring as a way of arguing against the non-conceptual nature of the content of know-how states, and given the difficulties in getting any explanatory mileage out of the notion of practical ways of thinking about ways of doing things, the most straightforward and plausible explanation of the difference between the functional roles that knowing-how and knowing-that states play in our mental life remains one which appeals to their having different kinds of content. ${ }^{14}$

Josefa Toribio Department of Logic, History and Philosophy of Science University of Barcelona 08001 Barcelona, Spain jtoribio@icrea.cat

\section{References}

Bengson, John and Marc Moffett. 2011a. Non-Propositional Intellectualism. In Knowing How: Essays on Knowledge, Mind, and Action, ed. by J. Bengson and M. A. Moffett. New York: OUP.

Bengson, John and Marc Moffett. 2011b. Two Conceptions of Mind and Action: Knowing How and the Philosophical Theory of Intelligence. In Knowing How: Essays on Knowledge, Mind, and Action, ed. by J. Bengson and M. A. Moffett.

${ }^{13}$ Thanks to an anonymous referee for pressing me on this point.

${ }^{14}$ Research for this paper was funded by the Spanish MCINN, under grants FFI2011-26853 and CSD2009- 0056, and by AGAUR, under grant 2014-SGR-81. 
New York: OUP.

Bermúdez, José. 1995. Nonconceptual Content: From Perceptual Experience to Subpersonal Computational States. Mind and Language 10: 333-369.

Brogaard, Berit. 2009. What Mary Did Yesterday: Reflections on Knowledge-wh. Philosophy and Phenomenological Research 78: 439-467.

Brogaard, Berit. 2011. Knowledge-How: A Unified Account. In Knowing How: Essays on Knowledge, Mind, and Action, ed. by J Bengson and M. A. Moffett. New York: OUP.

Carr, David. 1979. The Logic of Knowing How and Ability. Mind 88:394-409.

Evans, Gareth. 1982. The Varieties of Reference, ed. by]. McDowell. New York: OUP.

Fine, Kit. 2012. Guide to Ground. In Metaphysical Grounding: Understanding the Structure of Reality, ed. by F. Correia and B. Schnieder. Cambridge: CUP.

Fodor, Jerry. 2007. The Revenge of the Given. In Contemporary Debates in Philosophy of Mind, ed. by J. Cohen and B. McLaughlin. Malden, MA: Blackwell.

Hawley, Katherine. 2003. Success and Knowing How. American Philosophical Quarterly 40(1): 19-31.

Heck, Richard. 2000. Nonconceptual Content and the 'Space of Reasons.' The Philosophical Review, 109(4): 483-523.

Heck, Richard. 2007. Are There Different Kinds of Content? In Contemporary Debates in Philosophy of Mind, ed. by J. Cohen and B. McLaughlin. Malden, MA: Blackwell.

Kelly, Sean. 2000. Grasping at Straws: Motor Intentionality and the Cognitive Science of Skilled Behavior. In Heidegger, Coping, and Cognitive Science: Essays in Honor of Hubert L. Dreyfus - Vol. II, ed. by M. Wrathall and J. Malpas. Cambridge, MA: MIT Press.

Kelly, Sean. 2002. Merleau-Ponty on the Body. Ratio 15(4): 376-391.

Rescorla, Michael. 2009. Cognitive Maps and the Language of Thought. British Journal for the Philosophy of Science 60(2): 377-407.

Rosen, Gideon. 2010. Metaphysical Dependence: Grounding and Reduction. In Modality: Metaphysics, Logic, and Epistemology, ed. by B. Hale and A. Hoffmann. New York: OUP.

Ryle, Gilbert. 1946. Knowing How and Knowing That. Reprinted in his (1971) Gilbert Ryle: Collected Papers (vol. 2). New York: Barnes \& Noble.

Ryle, Gilbert. 1949. The Concept of Mind. Chicago: Chicago University Press.

Speaks, Jeff. 2005. Is There a Problem about Nonconceptual Content? The Philosophical Review, 114(3): 359-398.

Stanley, Jason. 2011a. Knowing (How). Nous 45(2): 207-238.

Stanley, Jason. 2011b. Know How. New York: OUP.

Stanley, Jason and Timothy Williamson. 2001. Knowing How. The Journal of Philosophy 97: 411-44.

Toribio, Josefa. 2008a. How Do We Know How? Philosophical Explorations, 11 (1): 39-52. Toribio, Josefa. 2008b. State versus Content: The Unfair Trial of Perceptual Nonconceptualism. Erkenntnis, 69 (3): 351-361. 